\title{
Gender Disparity in Structured Physical Activity and Overall Activity Level in Adolescence: Evaluation of Youth Risk Behavior Surveillance Data
}

\author{
Clare M. Lenhart, ${ }^{1}$ Alexandra Hanlon, ${ }^{2}$ Youjeong Kang, ${ }^{2}$ Brian P. Daly, ${ }^{3}$ \\ Michael D. Brown, ${ }^{4}$ and Freda Patterson ${ }^{1}$ \\ ${ }^{1}$ Department of Public Health, Temple University, Philadelphia, PA 19122, USA \\ ${ }^{2}$ School of Nursing, University of Pennsylvania, Philadelphia, PA 19104-4217, USA \\ ${ }^{3}$ School of Psychology, Drexel University, Philadelphia, PA 19104, USA \\ ${ }^{4}$ Department of Kinesiology and Nutrition, College of Applied Health Sciences, \\ University of Illinois at Chicago, Chicago, IL 60612-7249, USA
}

Correspondence should be addressed to Freda Patterson, fredap@temple.edu

Received 10 May 2012; Accepted 7 June 2012

Academic Editors: C. M. Buchalla and C. Murata

Copyright (c) 2012 Clare M. Lenhart et al. This is an open access article distributed under the Creative Commons Attribution License, which permits unrestricted use, distribution, and reproduction in any medium, provided the original work is properly cited.

\begin{abstract}
Background. Adolescent girls are less likely to meet physical activity recommendations than boys. This study examined the relative contribution of structured physical activity opportunities including physical education (PE) class and sports teams to overall activity levels for girls and boys. Methods. Data from 591 9th-12th grade students who completed the 2009 Philadelphia Youth Risk Behavior Survey were examined. Logistic regression was used to estimate the relationship between PE and sports teams and physical activity levels. Models were stratified by gender to estimate gender differences. Results. Girls were less likely to be active than boys: $27.9 \%$ of girls were sedentary as compared to $10.6 \%$ of boys. PE class was not related to activity levels among boys, while highly active girls were seven times more likely to participate in daily PE than were sedentary girls. Playing on one or more sports teams was associated with low-moderate and high activity in girls; among boys, sports team participation was only associated with high activity. Conclusions. The structured physical activity opportunities of PE and sports teams may contribute more to overall activity levels in girls than boys. A more rigorous assessment of this hypothesis is warranted to inform efforts to promote activity levels in girls.
\end{abstract}

\section{Introduction}

Gender differences in physical activity levels among youth are well documented [1-5]. Less than half the proportion of girls as compared to boys achieve the recommended 60 minutes or more of activity per day in the previous week $(11 \%$ versus $25 \%$, resp.) [5]. The likelihood of developing chronic diseases such as obesity, type 2 diabetes, and high blood pressure significantly increased in sedentary as compared to active youth [6], and given the gender disparity in physical activity levels, this can translate to a relatively increased risk among girls. Given that sedentary behaviors among youth continue into adulthood $[7,8]$, these negative health effects have the potential to become life-long afflictions, particularly among women. Understanding the factors that contribute to this gender disparity in physical activity, particularly among youth, could inform programming efforts.

Previous studies have examined the correlates and determinants of physical activity in adolescents $[1,9]$ and reported that, in addition to being male, other variables associated with increased levels of activity include being white, of younger age, having lower levels of depression, eating healthy foods, watching less television, and engaging in lower levels of tobacco and alcohol use [9-12]. Organizational influences such as involvement in physical education classes and sports teams are also important [9]. For example, school-based PE represented $11 \%$ of daily moderate-to-vigorous physical activity for boys while significantly less total MVPA was 
accumulated on days without school-based PE [13, 14]. However, what is less well understood is the extent to which these variables contribute to the gender disparity in physical activity specifically, whether participation in structured physical activity, such PE classes, is a stronger correlate of overall activity levels in girls than boys. Particularly as budget considerations leave some schools reconsidering the frequency of PE offerings, understanding the contribution of $\mathrm{PE}$ to overall physical activity may inform both practice and ongoing policy discussions.

Since girls are less likely to be active during unstructured time, such as recess, than boys [15], it could be argued that physical education in school may be a stronger correlate of activity levels for girls than boys and that reducing school time devoted to physical education [16] will only serve to widen the already pervasive gender gap in activity levels. To test this hypothesis, the current study sought to examine the relative contribution of organizational variables, specifically participation in physical education class and sports teams, to overall levels of physical activity for girls and boys, independent of the individual level variables demonstrated to relate to adolescent physical activity.

\section{Methods and Materials}

2.1. Study Design and Participants. This study uses crosssectional data from the Philadelphia Youth Risk Behavior Survey (YRBS) collected in the spring of 2009. In accordance with CDC sampling methodology all students in selected classrooms within designated schools were asked to voluntarily complete the self-report inventory [17]. Participants in this study represent 47 separate high school buildings from across the City of Philadelphia. All adolescents completing the Philadelphia YRBS who provided data for each of the variables included in this study were eligible for this secondary analysis, creating a sample size of 591 students for this study. Passive parental consent was obtained and surveys were completed anonymously [17]. This study was approved by the Institutional Review Board of Temple University and by the School District of Philadelphia.

2.2. Study Measures. Paper and pencil surveys were used to assess the study variables. Earlier versions of the YRBS have been assessed for, and have demonstrated, appropriate validity and reliability $[17,18]$. Low scoring items on previous versions have been removed or modified resulting in only the strongest items being carried forward to the 2009 survey [17].

Demographics. Self-reported grade, race/ethnicity, height and weight were evaluated. Body mass index was calculated as body mass $/$ height ${ }^{2}\left(\mathrm{~kg} / \mathrm{m}^{2}\right)$.

Psychological Variables. Past year depressive symptoms, suicidal ideation and suicide attempts $[19,20]$, were evaluated using three items that required a yes/no response.

Weight Perceptions and Concerns were evaluated [21, 22] using six items requiring a dichotomous (yes/no) response. Questions included. Do you consider yourself to be slightly/very overweight? In the last 30 days have you used strategies to lose weight, including (1) exercising, (2) eating less, (3) fasting for a 24-hour period, (4) taking pills, and (5) vomiting or use laxatives.

Drug Use. Current use (in the last 30-days) of tobacco, alcohol, marijuana, cocaine, heroin, methamphetamine, or ecstasy was evaluated using a single item for each substance with a binary response (0 times versus 1 or more times).

Fruit and Vegetable Intake. Dietary habits were considered with a series of questions asking. How many times in the past seven days did you eat... (1) fruit (2) green salad (3) potatoes and (4) other vegetable? Student responses to each question were collapsed into zero times versus one or more times. Previous work has established a positive association between eating a healthy diet and participation in physical activity $[9,23]$.

Screen Time. Screen time was assessed with two items: on an average school day, how many hours do you... (1) watch TV, and (2) play video or computer games or use a computer for something that is not school work? Responses were dichotomized as three or more hours/day or less than three hours per day.

Organizational Variables. The number of days per week that the student participated in physical education and the number of sports teams in which the student was a member were each evaluated.

Outcome Variable. The primary physical activity outcome was assessed with the question, "During the past seven days, on how many days were you physically active for a total of at least 60 minutes per day?" Responses were coded into one of three categories [24, 25] whereby students reporting zero days of activity were considered sedentary, those reporting activity on one to four days were considered low-moderately active, and those reporting activity on five to seven days were considered highly active. This self-report physical activity item has demonstrated moderate reliability in previous research [26].

2.3. Statistical Analysis. Demographic characteristics of the sample were generated. The association between the independent variables and physical activity level was estimated using chi-square $\left(\chi^{2}\right)$ tests of association for nominal or ordinal data or analysis of variance (ANOVA) for interval data. Independent variables that were significantly associated with physical activity were entered into a forward stepwise logistic regression model (.3 for entry). Separate logistic regression models that compared low-moderate levels of activity with sedentary behavior and high levels of activity with sedentary behavior were estimated. To evaluate genderspecific associations, the regression models were rerun with stratification for gender. All statistical analyses were conducted using SPSS version 19 (SPSS for Windows, Chicago, IL).

\section{Results}

3.1. Participant Characteristics. The study sample was comprised of the 5919th-12th grade students with complete data for all included study questions. Over half the sample was 
TABLE 1: Bivariate association of individual and organizational level variables with self-reported physical activity in the last week for 9th-12th grade girls and boys.

\begin{tabular}{|c|c|c|c|}
\hline & Sedentary & $\begin{array}{l}\text { Low-moderate } \\
\text { activity }\end{array}$ & High activity \\
\hline & $N=126(0$ days $)$ & $N=270(1-4$ Days $)$ & $N=195(5-7$ Days $)$ \\
\hline \multicolumn{4}{|l|}{ Individual level variables } \\
\hline \multicolumn{4}{|l|}{$* * *$ Sex } \\
\hline Female & $N=102(81 \%)$ & $N=168(62 \%)$ & $N=95(49 \%)$ \\
\hline Male & $N=24(19 \%)$ & $N=102(38 \%)$ & $N=100(51 \%)$ \\
\hline \multicolumn{4}{|l|}{ Overweight status $(\mathrm{BMI} \geq 25)$} \\
\hline Yes & $N=28(22 \%)$ & $N=57(21 \%)$ & $N=28(14 \%)$ \\
\hline No & $N=24(78 \%)$ & $N=213(79 \%)$ & $N=167(86 \%)$ \\
\hline \multicolumn{4}{|l|}{ Grade } \\
\hline 9th grade & $N=18(14 \%)$ & $N=53(19 \%)$ & $N=41(21 \%)$ \\
\hline 10th grade & $N=34(27 \%)$ & $N=91(34 \%)$ & $N=60(31 \%)$ \\
\hline 11th grade & $N=54(43 \%)$ & $N=103(38 \%)$ & $N=67(34 \%)$ \\
\hline 12th grade & $N=20(16 \%)$ & $N=23(9 \%)$ & $N=27(14 \%)$ \\
\hline \multicolumn{4}{|l|}{ Race } \\
\hline Caucasian & $N=19(15 \%)$ & $N=44(16 \%)$ & $N=33(17 \%)$ \\
\hline African American & $N=69(55 \%)$ & $N=134(50 \%)$ & $N=94(48 \%)$ \\
\hline Hispanic & $N=19(15 \%)$ & $N=49(18 \%)$ & $N=36(19 \%)$ \\
\hline Other & $N=19(15 \%)$ & $N=43(16 \%)$ & $N=32(16 \%)$ \\
\hline \multicolumn{4}{|l|}{ *Depression symptoms (sad 2 weeks in the last 12 months) } \\
\hline Yes & $N=39(31 \%)$ & $N=103(38 \%)$ & $N=57(29 \%)$ \\
\hline No & $N=87(69 \%)$ & $N=167(62 \%)$ & $N=138(71 \%)$ \\
\hline \multicolumn{4}{|c|}{ Suicidal ideation (considered suicide in the last 12 months) } \\
\hline Yes & $N=19(15 \%)$ & $N=38(14 \%)$ & $N=20(10 \%)$ \\
\hline No & $N=107(85 \%)$ & $N=232(86 \%)$ & $N=175(90 \%)$ \\
\hline \multicolumn{4}{|l|}{ Attempted suicide ( $1+$ times in the last 12 months) } \\
\hline Yes & $N=11(9 \%)$ & $N=17(6 \%)$ & $N=12(6 \%)$ \\
\hline No & $N=115(91 \%)$ & $N=253(94 \%)$ & $N=183(94 \%)$ \\
\hline \multicolumn{4}{|l|}{ Tobacco use in the last 30 days } \\
\hline Yes & $N=11(9 \%)$ & $N=29(11 \%)$ & $N=20(10 \%)$ \\
\hline No & $N=115(91 \%)$ & $N=241(89 \%)$ & $N=175(90 \%)$ \\
\hline \multicolumn{4}{|l|}{ *Alcohol use in the last 30 days } \\
\hline Yes & $N=40(32 \%)$ & $N=94(35 \%)$ & $N=54(28 \%)$ \\
\hline No & $N=86(68 \%)$ & $N=176(65 \%)$ & $N=141(72 \%)$ \\
\hline \multicolumn{4}{|l|}{ Marijuana use in the last 30 days } \\
\hline Yes & $N=16(13 \%)$ & $N=43(16 \%)$ & $N=31(16 \%)$ \\
\hline No & $N=110(87 \%)$ & $N=227(84 \%)$ & $N=164(84 \%)$ \\
\hline \multicolumn{4}{|l|}{${ }^{* *}$ Weight perception } \\
\hline Self-reports being slightly/very overweight & $N=43(34 \%)$ & $N=94(35 \%)$ & $N=39(20 \%)$ \\
\hline Does not self-report being slightly/very overweight & $N=83(66 \%)$ & $N=176(65 \%)$ & $N=156(80 \%)$ \\
\hline \multicolumn{4}{|l|}{ Weight concern } \\
\hline \multicolumn{4}{|l|}{${ }^{* *}$ Exercise to lose weight in the last 30 days } \\
\hline Yes & $N=48(38 \%)$ & $N=161(60 \%)$ & $N=123(63 \%)$ \\
\hline No & $N=78(62 \%)$ & $N=109(40 \%)$ & $N=72(37 \%)$ \\
\hline \multicolumn{4}{|l|}{${ }^{*}$ Eat less to lose weight } \\
\hline Yes & $N=38(30 \%)$ & $N=107(40 \%)$ & $N=72(37 \%)$ \\
\hline No & $N=88(70 \%)$ & $N=163(60 \%)$ & $N=123(63 \%)$ \\
\hline
\end{tabular}


TABle 1: Continued.

\begin{tabular}{|c|c|c|c|}
\hline & Sedentary & $\begin{array}{l}\text { Low-moderate } \\
\text { activity }\end{array}$ & High activity \\
\hline & $N=126(0$ days $)$ & $N=270(1-4$ Days $)$ & $N=195(5-7$ Days $)$ \\
\hline \multicolumn{4}{|c|}{ *Fast to lose weight } \\
\hline Yes & $N=8(6 \%)$ & $N=30(11 \%)$ & $N=12(6 \%)$ \\
\hline No & $N=118(94 \%)$ & $N=240(89 \%)$ & $N=183(94 \%)$ \\
\hline \multicolumn{4}{|c|}{ Take pills to lose weight } \\
\hline Yes & $N=5(4 \%)$ & $N=7(3 \%)$ & $N=6(3 \%)$ \\
\hline No & $N=121(96 \%)$ & $N=263(97 \%)$ & $N=189(97 \%)$ \\
\hline \multicolumn{4}{|c|}{ Vomit to lose weight } \\
\hline Yes & $N=4(3 \%)$ & $N=13(5 \%)$ & $N=7(4 \%)$ \\
\hline No & $N=122(97 \%)$ & $N=257(95 \%)$ & $N=188(96 \%)$ \\
\hline \multicolumn{4}{|c|}{ Dietary behaviors } \\
\hline \multicolumn{4}{|c|}{${ }^{* *}$ Ate fruit in the last 7 days } \\
\hline Yes & $N=97(77 \%)$ & $N=230(85 \%)$ & $N=169(87 \%)$ \\
\hline No & $N=29(23 \%)$ & $N=40(15 \%)$ & $N=26(13 \%)$ \\
\hline \multicolumn{4}{|c|}{ Ate green salad in the last 7 days } \\
\hline Yes & $N=62(49 \%)$ & $N=139(52 \%)$ & $N=112(57 \%)$ \\
\hline No & $N=64(51 \%)$ & $N=131(49 \%)$ & $N=83(43 \%)$ \\
\hline \multicolumn{4}{|c|}{ *** Ate potatoes in the last 7 days } \\
\hline Yes & $N=56(44 \%)$ & $N=157(58 \%)$ & $N=119(61 \%)$ \\
\hline No & $N=70(56 \%)$ & $N=113(42 \%)$ & $N=76(39 \%)$ \\
\hline \multicolumn{4}{|c|}{ *Ate carrots in the last 7 days } \\
\hline Yes & $N=28(22 \%)$ & $N=89(33 \%)$ & $N=62(32 \%)$ \\
\hline No & $N=98(78 \%)$ & $N=181(67 \%)$ & $N=133(68 \%)$ \\
\hline \multicolumn{4}{|c|}{ *Ate other veggies in the last 7 days } \\
\hline Yes & $N=95(76 \%)$ & $N=227(84 \%)$ & $N=159(82 \%)$ \\
\hline No & $N=31(25 \%)$ & $N=43(16 \%)$ & $N=36(18 \%)$ \\
\hline \multicolumn{4}{|c|}{$* *$ Watched television for $\geq 3$ hours/day } \\
\hline Yes & $N=77(61 \%)$ & $N=130(48 \%)$ & $N=92(47 \%)$ \\
\hline No & $N=49(39 \%)$ & $N=140(52 \%)$ & $N=103(53 \%)$ \\
\hline \multicolumn{4}{|c|}{ Organizational variable } \\
\hline \multicolumn{4}{|c|}{$* * *$ Played in $\geq 1$ sport team in the last 12 months } \\
\hline Yes & $N=29(23 \%)$ & $N=100(37 \%)$ & $N=117(60 \%)$ \\
\hline No & $N=97(77 \%)$ & $N=170(63 \%)$ & $N=78(40 \%)$ \\
\hline \multicolumn{4}{|c|}{$* * *$ Did $\mathrm{PE} \geq 1$ in average week } \\
\hline Yes & $N=39(31 \%)$ & $N=83(31 \%)$ & $N=96(49 \%)$ \\
\hline No & $N=87(69 \%)$ & $N=187(69 \%)$ & $N=99(51 \%)$ \\
\hline \multicolumn{4}{|c|}{${ }^{* * *}$ Did PE every day in the lastweek } \\
\hline Yes & $N=15(12 \%)$ & $N=39(14 \%)$ & $N=58(30 \%)$ \\
\hline No & $N=111(88 \%)$ & $N=231(86 \%)$ & $N=137(70 \%)$ \\
\hline
\end{tabular}

${ }^{*} P<0.05 ;{ }^{* *} P<0.01 ; * * * P<0.001$.

female $(N=365,61.8 \%)$. Nineteen percent $(N=112)$ of the students were in 9th grade, $31 \%(N=185)$ in 10 th grade, $38 \%(N=224)$ in 11 th grade, and $12 \%(N=70)$ in 12 th grade. Half the sample reported being African American $(50 \% ; N=297), 18 \%$ indicated being Hispanic $(N=$ $104)$, and $16 \%$ classified themselves as Caucasian $(N=96)$. Nineteen percent of the students $(N=113)$ were overweight, and one-third (33\%; $N=195)$ self-reported achieving 60 minutes of moderate to vigorous physical activity on five or more days of the week. Descriptive characteristics for the study variables are provided in Table 1.

3.2. Bivariate Analysis. The association between the independent variables evaluated and levels of physical activity is provided in Table 1 . Of relevance to this investigation, a greater proportion of females than males reported being 
TABLE 2: Logistic regression to show relative association between independent variables and sedentary versus low-moderate and sedentary versus high levels of activity.

\begin{tabular}{|c|c|c|c|c|c|c|}
\hline \multirow[t]{2}{*}{ Variable } & \multicolumn{3}{|c|}{$\begin{array}{l}\text { Low-moderate activity } \\
\qquad(N=270)\end{array}$} & \multicolumn{3}{|c|}{$\begin{array}{l}\text { High activity } \\
(N=321)\end{array}$} \\
\hline & S.E. & $\operatorname{Exp}(\beta)$ & $P$ & S.E. & $\operatorname{Exp}(\beta)$ & $P$ \\
\hline Exercise to lose weight in the last 30 days & .27 & 2.69 & $<.01$ & 0.33 & 2.88 & $<.01$ \\
\hline Eat less to lose weight in the last 30 days & 0.30 & 1.62 & .10 & 0.36 & 1.27 & .51 \\
\hline Trying to lose weight & 0.32 & 0.59 & .10 & 0.38 & 0.65 & .26 \\
\hline Ate potatoes in the last 7 days & 0.23 & 1.58 & .05 & 0.28 & 1.80 & .03 \\
\hline Watched $3+$ hours of TV per day & 0.24 & 0.72 & .17 & 0.28 & 0.51 & .02 \\
\hline Participated in PE Class $1+$ day/week & 0.31 & 0.72 & 0.29 & 0.35 & 0.88 & 0.72 \\
\hline Played on $\geq 1$ sport team in the last year & 0.27 & 1.75 & 0.04 & 0.29 & 3.20 & $<0.01$ \\
\hline Participated in PE class every day & 0.43 & 1.20 & 0.67 & 0.46 & 3.45 & $<0.01$ \\
\hline Grade & 0.14 & 0.73 & 0.02 & 0.15 & 0.92 & 0.58 \\
\hline Overweight & 0.30 & 0.94 & 0.83 & 0.37 & 1.59 & 0.21 \\
\hline \multirow[t]{2}{*}{ Sex (1: female; $2:$ male) } & 0.28 & 2.81 & $<0.01$ & 0.31 & 3.20 & $<0.01$ \\
\hline & \multicolumn{3}{|c|}{$R^{2}=0.13 ; P<.01$} & \multicolumn{3}{|c|}{$R^{2}=0.27 ; P<.01$} \\
\hline
\end{tabular}

Unless otherwise stated, No: 0 and Yes: 1.

sedentary, while a greater proportion of males than females reported being highly active (Figure 1). The number of sports teams was found to be highly associated with overall physical activity levels $\left(\chi^{2}(2)=47.4 ; P<.01\right)$, specifically, among students who reported being on one or more sports teams in the last year, $92 \%$ were active ( $41 \%$ low-moderate activity; $48 \%$ highly active) whereas of students who did not belong to a team, $72 \%$ were active ( $49 \%$ low-moderate activity, $23 \%$ highly active). Similarly, attending physical education class at least once a week $\left(\chi^{2}(2)=19.05 ; P<.01\right)$ and daily $\left(\chi^{2}(2)=\right.$ 22.4; $P<.01)$ was also highly associated with overall activity levels. Among students who reported attending physical education class at least once a week, $82 \%$ were active $38 \%$ low-moderate activity; $44 \%$ highly active) whereas of those students who did not attend physical education class on a weekly basis, $76 \%$ were active (50\% low-moderate activity, $27 \%$ highly active). A similar trend was found for attending physical education class on a daily basis.

3.3. Regression Models. The overall logistic regression models of low-moderate and high activity are provided in Table 2. A review of the gender-specific model data (provided in Table 3 ) is provided here.

Correlates of Low-Moderate and High Levels of Activity in Girls. Consistent with the overall model of low-moderate activity, low-moderately active girls were more likely to report exercising to lose weight $(\operatorname{Exp}(\beta)=3.36, P<.01)$, eating potatoes in the last 7 days $(\operatorname{Exp}(\beta)=1.74, P=.05)$, playing on at least one sports team in the last year $(\operatorname{Exp}(\beta)=$ 2.14, $P=.02)$, and being in a lower grade in school $(\operatorname{Exp}(\beta)$ $=.65, P=.01)$ as compared to sedentary girls. Specific to this "girls-only" model are data showing that these lowmoderately active girls, as compared to sedentary girls, are more likely to report eating less to lose weight $(\operatorname{Exp}(\beta)=$ $2.81, P<.01)$ but less likely to report trying to lose weight

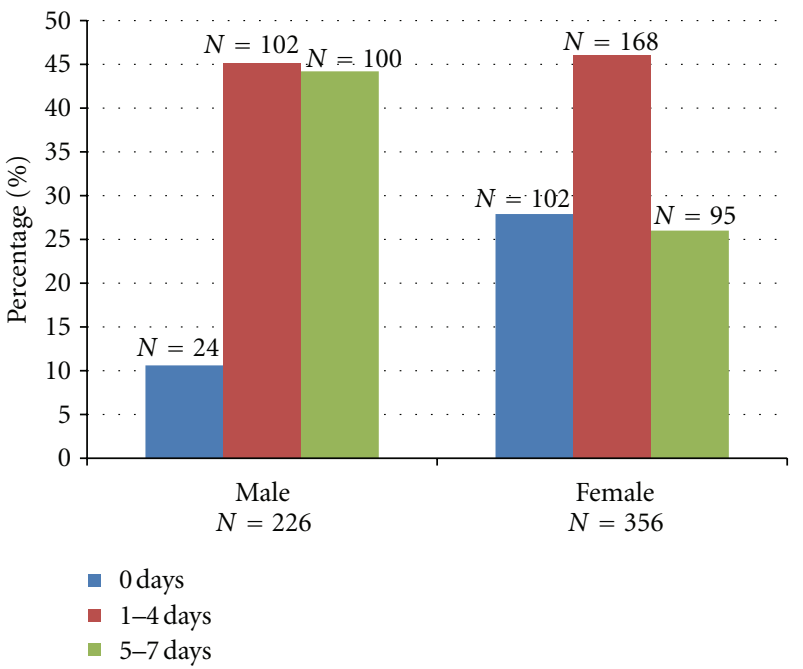

Figure 1: Gender differences in physical activity levels. $\chi^{2}=$ 33.7; $P<.01$.

$(\operatorname{Exp}(\beta)=2.88, P<.01)$ and participating in PE class at least one day each week $(\operatorname{Exp}(\beta)=.44, P=.03)$. Compared to sedentary girls, highly active girls are more likely to report exercising to lose weight $(\operatorname{Exp}(\beta)=2.46, P=.03)$, playing on at least one sport team in the last year $(\operatorname{Exp}(\beta)=3.24$, $P<.01)$, and participating in PE class every day $(\operatorname{Exp}(\beta)=$ 7.06, $P<.01$ ). Highly active girls are also about two-thirds less likely to report watching television for at least three hours per day $(\operatorname{Exp}(\beta)=0.34, P<.01)$ than sedentary girls.

Correlates of Low-Moderate and High Levels of Activity in Boys. The logistic regression model of low-moderate activity for the boys in the sample was not significant, and none of the independent variables included in the model emerged 
TABLE 3: Logistic regression to show relative association between the independent variables and sedentary versus moderate and sedentary versus high levels of activity in girls and boys.

\begin{tabular}{|c|c|c|c|c|c|c|}
\hline \multirow[b]{2}{*}{ Variable } & \multicolumn{3}{|c|}{ Low-moderate activity } & \multicolumn{3}{|c|}{ High activity } \\
\hline & S.E. & $\operatorname{Exp}(\beta)$ & $P$ & S.E. & $\operatorname{Exp}(\beta)$ & $P$ \\
\hline \multicolumn{7}{|c|}{ (a) Girls } \\
\hline Exercise to lose weight in the last 30 days & 0.327 & 3.36 & 0.000 & 0.404 & 2.464 & 0.026 \\
\hline Eat less to lose weight in the last 30 days & 0.366 & 2.81 & 0.005 & 0.460 & 2.050 & 0.119 \\
\hline Trying to lose weight & 0.399 & 0.36 & 0.010 & 0.483 & 0.642 & 0.359 \\
\hline Ate potatoes in the last 7 days & 0.280 & 1.74 & 0.047 & 0.347 & 1.918 & 0.061 \\
\hline Watched $3+$ hours of TV per day & 0.298 & 0.67 & 0.174 & 0.365 & 0.342 & 0.003 \\
\hline Participated in PE class $1+$ day/week & 0.378 & 0.44 & 0.030 & 0.452 & 0.603 & 0.263 \\
\hline Played on $\geq 1$ sport team in the last year & 0.322 & 2.14 & 0.018 & 0.369 & 3.243 & 0.001 \\
\hline Participated in PE class every day & 0.542 & 1.73 & 0.312 & 0.593 & 7.064 & 0.001 \\
\hline Grade & 0.170 & 0.65 & 0.012 & 0.191 & .842 & 0.368 \\
\hline \multirow[t]{2}{*}{ Overweight } & 0.345 & 1.000 & 1.000 & 0.479 & 2.463 & 0.060 \\
\hline & \multicolumn{3}{|c|}{$R^{2}=0.18 ; P<0.01$} & \multicolumn{3}{|c|}{$R^{2}=0.27 ; P<0.01$} \\
\hline \multicolumn{7}{|c|}{ (b) Boys } \\
\hline Exercise to lose weight in the last 30 days & 0.600 & 1.87 & 0.296 & 0.614 & 4.200 & .019 \\
\hline Eat less to lose weight in last 30 days & 0.606 & 0.33 & 0.070 & 0.617 & 0.585 & 0.385 \\
\hline Trying to lose weight & 0.669 & 1.72 & 0.418 & 0.692 & 0.617 & 0.486 \\
\hline Ate potatoes in the last 7 days & 0.481 & 1.41 & 0.473 & 0.519 & 1.738 & 0.287 \\
\hline Watched $3+$ hours of TV per day & 0.480 & 0.91 & 0.838 & 0.520 & 1.157 & 0.779 \\
\hline Participated in PE class $1+$ day/week & 0.701 & 1.75 & 0.425 & 0.761 & 2.597 & 0.210 \\
\hline Played on $\geq 1$ sport team in the last year & 0.509 & 1.15 & 0.783 & 0.512 & 2.785 & 0.046 \\
\hline Participated in PE class every day & 0.831 & 0.51 & 0.418 & 0.868 & 0.848 & 0.849 \\
\hline Grade & 0.254 & 1.06 & 0.809 & 0.260 & 0.975 & 0.923 \\
\hline \multirow[t]{2}{*}{ Overweight } & 0.725 & 0.68 & 0.597 & 0.723 & 0.877 & 0.856 \\
\hline & \multicolumn{3}{|c|}{$R^{2}=0.05 ; P=.66(\mathrm{~ns})$} & \multicolumn{3}{|c|}{$R^{2}=0.13 ; P=.06$} \\
\hline
\end{tabular}

as being relatively significant correlates. In the logistic regression model of high activity, the results showed that highly active boys were more likely to report exercising to lose weight $(\operatorname{Exp}(\beta)=4.20, P=.02)$ and playing on at least one sports team in the last year $(\operatorname{Exp}(\beta)=2.79, P=.05)$ than their sedentary counterparts.

\section{Discussion and Conclusion}

The primary purpose of this study was to examine whether the structured physical activity opportunities of sports team participation and school-based PE contributed differently to the physical activity level of girls versus boys, independent of individual level variables. Consistent with previous work [3, 27-29], these results demonstrate that males were significantly more likely to be active than females, and this association was even more pronounced in the high activity (versus sedentary) group (see Table 2). Of relevance to our understanding of the correlates of gender differences in adolescent activity, results suggested that playing on sports teams and participation in PE class contributed differently to overall levels of activity for boys and girls.

Playing on at least one sport team in the last year was significantly associated with being active (versus sedentary): respondents who were highly active were over three times more likely, and those who engaged in low-moderate activity were almost twice as likely, to report being on at least one sport team than sedentary individuals. In terms of gender differences, highly active girls were over three times as likely to report playing on at least one sport team in the last year as compared to sedentary girls, while low-moderately active girls were more than twice as likely to play on at least one sport team than sedentary girls $(P=.001$ and .02 , resp. $)$. Among boys, participation in one or more sport teams was related to high, but not to low-moderate, levels of physical activity.

Several lines of evidence can help with the interpretation of these data. First, adolescent boys have been shown to achieve greater physical activity participation during unstructured periods of the day, including recess and after school, than do girls [15]. Thus, boys may achieve lowmoderate levels of physical activity without benefit of sports team participation whereas girls may benefit from the impetus of an organized sports team to achieve increased physical activity participation. Second, sports teams also represent a form of social support for physical activity. Given that social support is positively associated with physical activity in adolescent girls $[30,31]$, promoting team participation and the sense of "belonging" inherent with that may be a strategy for promoting activity in adolescent girls. 
Participation in daily physical education class was significantly associated with high levels of activity; however, this effect was not found for participating in $\mathrm{PE}$ on at least one day per week. When this relationship was examined in the gender-specific models, physical education participation was not related to overall levels of physical activity for boys, while highly active girls were seven times more likely $(P=.001)$ to report participating in PE class every day than sedentary girls. Conversely, low-moderately active girls were half as likely to report participating in PE on one or more days of the week.

That daily PE confers increased likelihood of high activity is not surprising; what is surprising is that in the genderstratified models, this relationship is only evident for highly active girls. One hypothesis from these data is that the active boys are accumulating activity time outside of PE class. Related to this premise are data showing that, first, boys are more likely to engage in leisure-time physical activity than girls [15] and, second, only half of PE class time actually includes moderate-vigorous activity $[32,33]$. On this basis, it is plausible that the active boys in this sample accumulated their active time outside the classroom and that among girls only those who were sufficiently motivated fully engaged in higher levels of activity. This line of interpretation is quite hypothetical, but does highlight the hypothesis that PE may contribute differently to overall activity levels for girls versus boys, and this certainly warrants further investigation.

Results from this exploratory study should be interpreted with consideration of several limiting factors. First, these data are cross-sectional in nature and as such the significant relationships reported are associations and should be considered hypothesis generating. Second, all data are self-report and particularly in the case of physical activity levels are subject to recall bias. Third, while the intent was to elucidate gender differences in the role of the organizational level variables of sports team participation and physical education classes on physical activity levels, independent of individual level influences on physical activity, this was not completely accomplished. There are several individual level variables known to relate to adolescent physical activity levels that were not included in this study (e.g., parental support for physical activity [34].

The implications of these hypothesis-generating data can be summarized in three points. First, these data support the hypothesis that correlates of adolescent physical activity need to be examined in a gender-stratified way so that gender-specific programs can be refined. Second, organized physical activity events and outlets may play a larger role in promoting physical activity levels in girls than boys. Third, physical education class may contribute differently to the overall activity level of girls relative to boys and thus decreases in the frequency of school-based PE may serve to differentially impact female students. Data from this study provide some initial support for these hypotheses. Future trials are needed to fully evaluate this premise, perhaps in the context of a longitudinal trial that also includes younger children.

\section{Acknowledgments}

The authors thank Dr. Deborah Nelson, Associate Professor at Temple University, for her input on the conceptualization of the study research questions. The authors also extend their gratitude to Judith Peters of the Philadelphia School District as well as the students who completed the YRBS. This paper is Supported in part by the Department of Public Health, Temple University and HyMAP. Data collection was supported by a CDC ARREST Grant to the School District of Philadelphia.

\section{References}

[1] K. Van Der Horst, M. J. C. A. Paw, J. W. R. Twisk, and W. Van Mechelen, "A brief review on correlates of physical activity and sedentariness in youth," Medicine and Science in Sports and Exercise, vol. 39, no. 8, pp. 1241-1250, 2007.

[2] S. C. Dumith, V. V. Ramires, M. A. Souza et al., "Overweight/obesity and physical fitness among children and adolescents," Journal of Physical Activity \& Health, vol. 7, no. 5, pp. 641-648, 2010.

[3] P. J. Wenthe, K. F. Janz, and S. M. Levy, "Gender similarities and differences in factors associated with adolescent moderate-vigorous physical activity," Pediatric Exercise Science, vol. 21, no. 3, pp. 291-304, 2009.

[4] M. Frenn, S. Malin, A. M. Villarruel et al., "Determinants of physical activity and low-fat diet among low income African American and Hispanic middle school students," Public Health Nursing, vol. 22, no. 2, pp. 89-97, 2005.

[5] Centers for Disease Control and Prevention, "Surveillance summaries," MMWR-Recommendations and Reports, vol. 59, 2010.

[6] L. B. Andersen, S. A. Anderssen, S. Brage, U. Ekelund, and K. Froberg, "Physical activity and clustering of CVD risk factors-secondary publication,” Ugeskrift for Laeger, vol. 168, no. 47, pp. 4101-4103, 2006.

[7] R. M. Malina and T. Bielicki, "Retrospective longitudinal growth study of boys and girls active in sport," Acta Paediatrica, International Journal of Paediatrics, vol. 85, no. 5, pp. 570-576, 1996.

[8] R. Telama, X. Yang, J. Viikari, I. Välimäki, O. Wanne, and O. Raitakari, "Physical activity from childhood to adulthood: a 21-year tracking study," American Journal of Preventive Medicine, vol. 28, no. 3, pp. 267-273, 2005.

[9] J. F. Sallis, J. J. Prochaska, and W. C. Taylor, "A review of correlates of physical activity of children and adolescents," Medicine and Science in Sports and Exercise, vol. 32, no. 5, pp. 963-975, 2000.

[10] S. G. Trost, R. Saunders, and D. S. Ward, "Determinants of physical activity in middle school children," American Journal of Health Behavior, vol. 26, no. 2, pp. 95-102, 2002.

[11] G. F. Dunton, M. Cousineau, and K. D. Reynolds, "The intersection of public policy and health behavior theory in the physical activity arena," Journal of Physical Activity and Health, vol. 7, supplement 1, pp. S91-S98, 2010.

[12] J. A. Serrano-Sanchez, S. M. Trujillo, A. L. Navarro et al., "Associations between screen time and physical activity among Spanish adolescents," PLoS ONE, vol. 6, no. 9, Article ID e24453, 2011. 
[13] E. E. Wickel and J. C. Eisenmann, "Maturity-related differences in physical activity among 13- to 14-year-old adolescents," Pediatric Exercise Science, vol. 19, no. 4, pp. 384-392, 2007.

[14] E. E. Wickel and J. C. Eisenmann, "Contribution of youth sport to total daily physical activity among 6- to 12-yr-old boys," Medicine and Science in Sports and Exercise, vol. 39, no. 9, pp. 1493-1500, 2007.

[15] J. Mota, P. Silva, M. P. Santos, J. C. Ribeiro, J. Oliveira, and J. A. Duarte, "Physical activity and school recess time: differences between the sexes and the relationship between children's playground physical activity and habitual physical activity," Journal of Sports Sciences, vol. 23, no. 3, pp. 269-275, 2005.

[16] L. Kann, N. D. Brener, and D. D. Allensworth, "Health education: results from the school health policies and programs study 2000," Journal of School Health, vol. 71, no. 7, pp. 266278, 2001.

[17] Centers for Disease Control and Prevention, "Methodology of the youth risk behavior surveillance system," MMWRRecommendations and Reports, vol. 53, p. RR-12, 2004.

[18] N. D. Brener, J. L. Collins, L. Kann, C. W. Warren, and B. I. Williams, "Reliability of the youth risk behavior survey questionnaire," American Journal of Epidemiology, vol. 141, no. 6, pp. 575-580, 1995.

[19] T. R. Simon, K. E. Powell, and A. C. Swann, "Involvement in physical activity and risk for nearly lethal suicide attempts," American Journal of Preventive Medicine, vol. 27, no. 4, pp. 310-315, 2004.

[20] L. A. Taliaferro, M. E. Eisenberg, K. E. Johnson, T. F. Nelson, and D. Neumark-Sztainer, "Sport participation during adolescence and suicide ideation and attempts," International Journal of Adolescent Medicine and Health, vol. 23, no. 1, pp. 3-10, 2011.

[21] D. Neumark-Sztainer, M. Story, P. J. Hannan, C. L. Perry, and L. M. Irving, "Weight-related concerns and behaviors among overweight and nonoverweight adolescents: implications for preventing weight-related disorders," Archives of Pediatrics and Adolescent Medicine, vol. 156, no. 2, pp. 171-178, 2002.

[22] Y. Wang, H. Liang, and X. Chen, "Measured body mass index, body weight perception, dissatisfaction and control practices in urban, low-income African American adolescents," BMC Public Health, vol. 9, article 183, 2009.

[23] G. F. Dunton, R. Lagloire, and T. Robertson, "Nutrition using the RE-AIM framework to evaluate the statewide dissemination of a school-based physical activity and nutrition curriculum: 'Exercise your options,', American Journal of Health Promotion, vol. 23, no. 4, pp. 229-232, 2009.

[24] W. B. Strong, R. M. Malina, C. J. R. Blimkie et al., "Evidence based physical activity for school-age youth," Journal of Pediatrics, vol. 146, no. 6, pp. 732-737, 2005.

[25] D. K. Eaton, L. Kann, S. Kinchen et al., "Youth risk behavior surveillance-United States, 2007," MMWR-Surveillance Summaries, vol. 57, no. 4, pp. 1-131, 2008.

[26] S. J. Biddle, T. Gorely, N. Pearson, and F. C. Bull, "An assessment of self-reported physical activity instruments in young people for population surveillance: project ALPHA," International Journal of Behavioral Nutrition and Physical Activity, vol. 8, article 1, 2011.

[27] G. F. Dunton, A. A. Atienza, J. Tscherne, and D. Rodriguez, "Identifying combinations of risk and protective factors predicting physical activity change in high school students," Pediatric Exercise Science, vol. 23, no. 1, pp. 106-121, 2011.
[28] S. C. Dumith, M. R. Domingues, D. P. Gigante, P. C. Hallal, A. M. B. Menezes, and H. W. Kohl, "Prevalence and correlates of physical activity among adolescents from Southern Brazil," Revista de Saude Publica, vol. 44, no. 3, pp. 457-467, 2010.

[29] R. R. Pate, J. Stevens, L. S. Webber et al., "Age-related change in physical activity in adolescent girls," Journal of Adolescent Health, vol. 44, no. 3, pp. 275-282, 2009.

[30] C. Craggs, E. M. van Sluijs, K. Corder, J. R. Panter, A. P. Jones, and S. J. Griffin, "Do children's individual correlates of physical activity differ by home setting?" Health and Place, vol. 17, no. 5, pp. 1105-1112, 2011.

[31] K. K. Davison and R. Jago, "Change in parent and peer support across ages 9 to $15 \mathrm{yr}$ and adolescent girls' physical activity," Medicine and Science in Sports and Exercise, vol. 41, no. 9, pp. 1816-1825, 2009.

[32] T. L. McKenzie, E. J. Stone, H. A. Feldman et al., "Effects of the CATCH physical education intervention: teacher type and lesson location," American Journal of Preventive Medicine, vol. 21, no. 2, pp. 101-109, 2001.

[33] D. P. Coe, J. M. Pivarnik, C. J. Womack, M. J. Reeves, and R. M. Malina, "Effect of physical education and activity levels on academic achievement in children," Medicine and Science in Sports and Exercise, vol. 38, no. 8, pp. 1515-1519, 2006.

[34] P. Mulhall, J. Reis, and S. Begum, "Early adolescent participation in physical activity: correlates with individual and family characteristics," Journal of Physical Activity and Health, vol. 8, no. 2, pp. 244-252, 2011. 


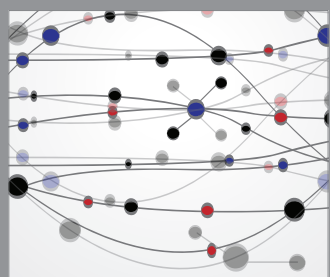

The Scientific World Journal
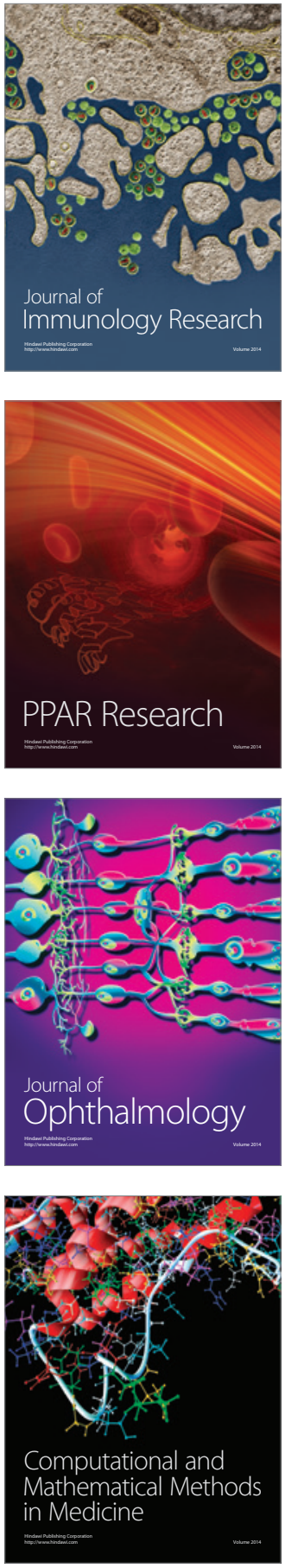

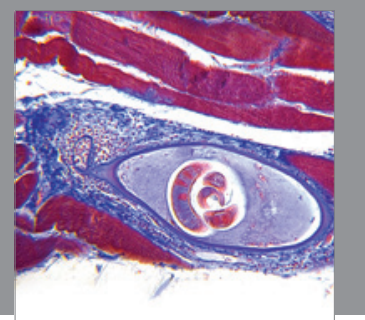

Gastroenterology

Research and Practice
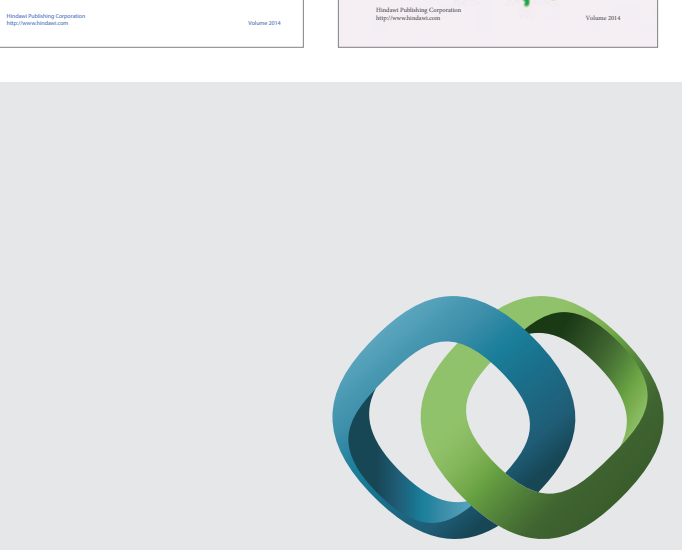

\section{Hindawi}

Submit your manuscripts at

http://www.hindawi.com
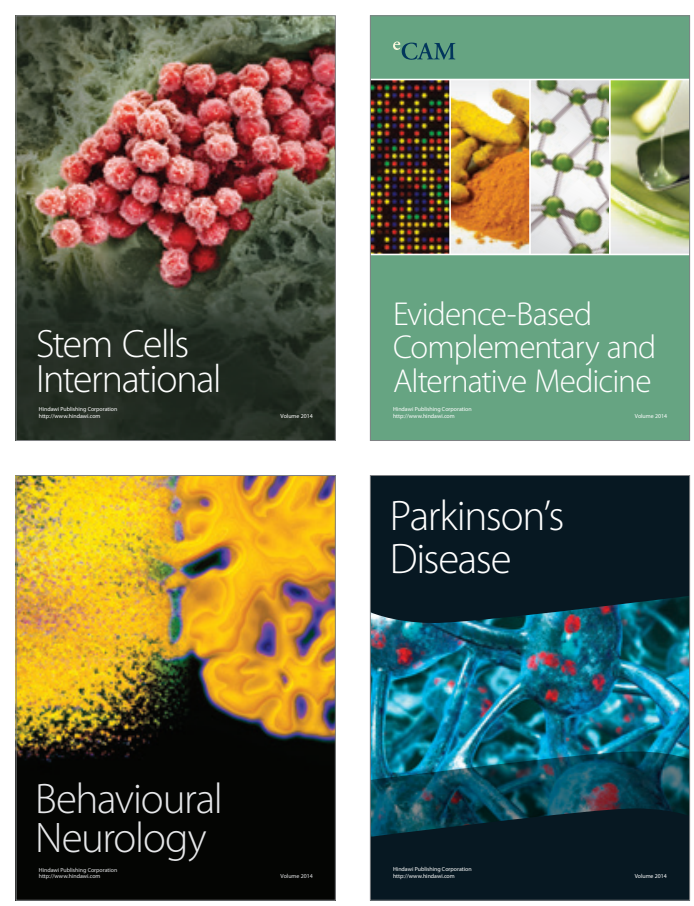

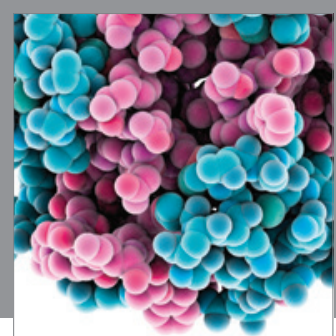

Journal of
Diabetes Research

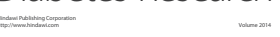

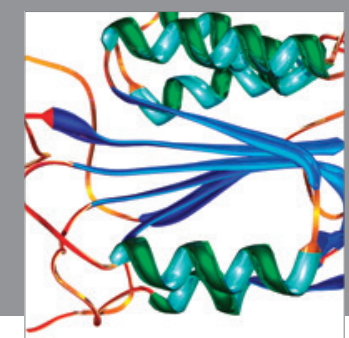

Disease Markers
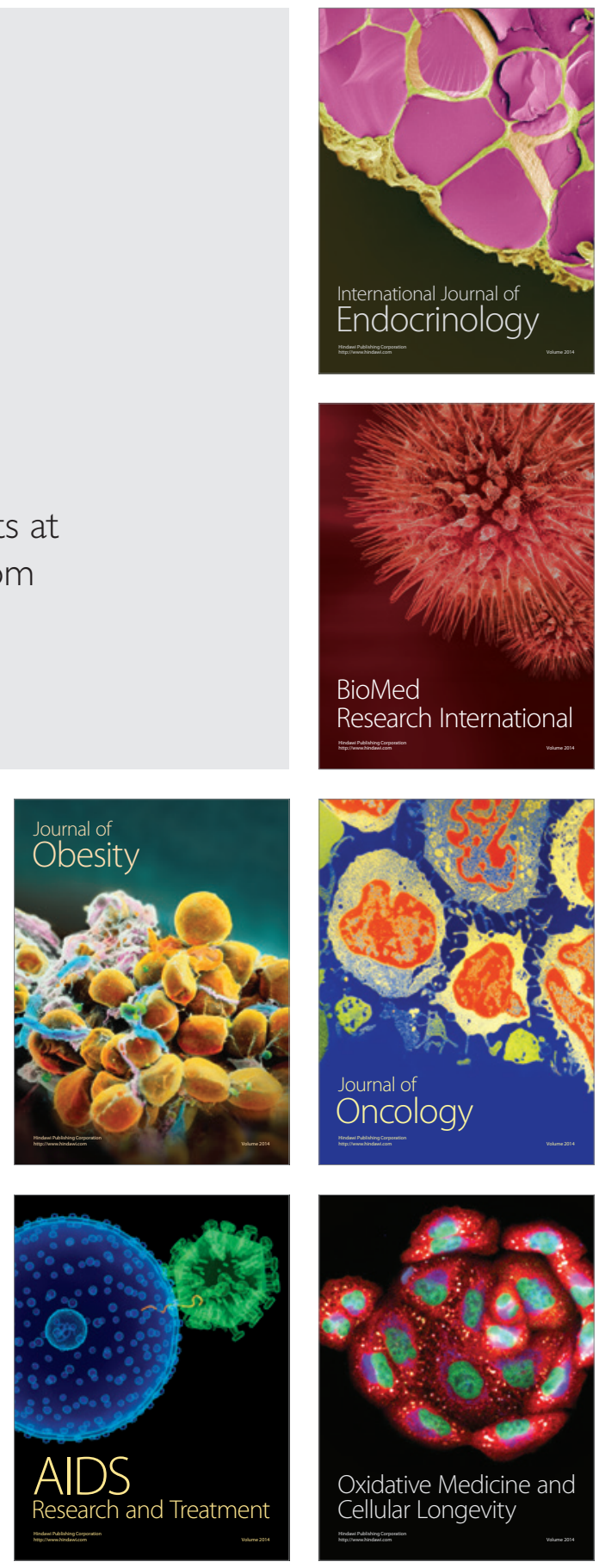